\title{
Design of a device to simulate environmental influences on the course of brake tests
}

\author{
Jozef Harušinec ${ }^{1, *}$, Andrej Suchánek ${ }^{1}$, Mária Loulová ${ }^{1}$, Peter Strážovec $^{1}$ \\ ${ }^{1}$ University of Žilina, Faculty of Mechanical Engineering, Department of Transport and Handling \\ Machines, Univerzitná 8215/1, 01026 Žilina, Slovak Republic
}

\begin{abstract}
When performing the technical tests of the brake system under laboratory conditions, it is necessary to create the same conditions as those in operation. The friction coefficient is dependent on a number of parameters, including airflow during ride and weather conditions. Therefore, during the take-over tests, both these conditions are obligatory to simulate. This paper describes the design of the chamber, which will allow the test stand RAILBCOT to carry out the so-called dry and wet tests with airflow as during real-life ride. It also isolates the acoustic emission and emission of braking material to the surrounding area when tested.
\end{abstract}

Keywords: railway wheel, brake block, structural analysis

\section{Introduction}

One of the basic requirements of European railways is reduction of the noise generated in wheel-rail contact in the service of freight railway wagons $[1,2,3]$.

Since the beginning of the service it was known, that a significant reduction of freight wagons noise can be achieved by replacing iron cast brake blocks with brake blocks made from composite materials. Currently, brake blocks made from composite materials are used in service $[4,5,8,12,13]$. However, the value of their friction coefficient is different from the one of the iron cast brake block. If composite materials are used, there is a change in braking forces acting on wheels $[7,14,16,17,18]$. These types of composite brake blocks (K-block) have a higher friction coefficient than iron cast brake blocks. In service, it is necessary to adjust the vehicle braking system to the composite brake block of K-type, which is financially expensive $[9,11,15,19,22]$. For these reasons, it was proposed to use K-block for new vehicles. For existing vehicles, brake blocks made from composite materials with a similar friction coefficient as iron cast brake blocks (LL-blocks) have to be used to avoid the adaptation of the braking system by using a "silent" K-block.

\footnotetext{
* Corresponding author: jozef.harusinec@fstroj.uniza.sk

Reviewers: Robert Grega, Ksawery Szykiedans
} 


\section{Test stand of braking components RAILBCOT and simulator of equivalent railway traffic load SIMRAIL}

The RAILBCOT test stand is a device that works on the adhesion principle [6, 10, 20, 21]. The main purpose is to analyze the change in geometry of the railway wheelset tread profiles due to wear caused by simulated operating loads under laboratory conditions. Along with the wear of the tread profile, brake block wear will be monitored for different braking modes. The purpose of the test stand is to load the wheelset with an adequate force load, simulated by a combination of engine torque, wheel load change, track gauge free channel size change, wheelset attack angle change, and variable braking mode based on the independent action of four brake units with a change of configuration, shape and the material composition of the brake blocks.

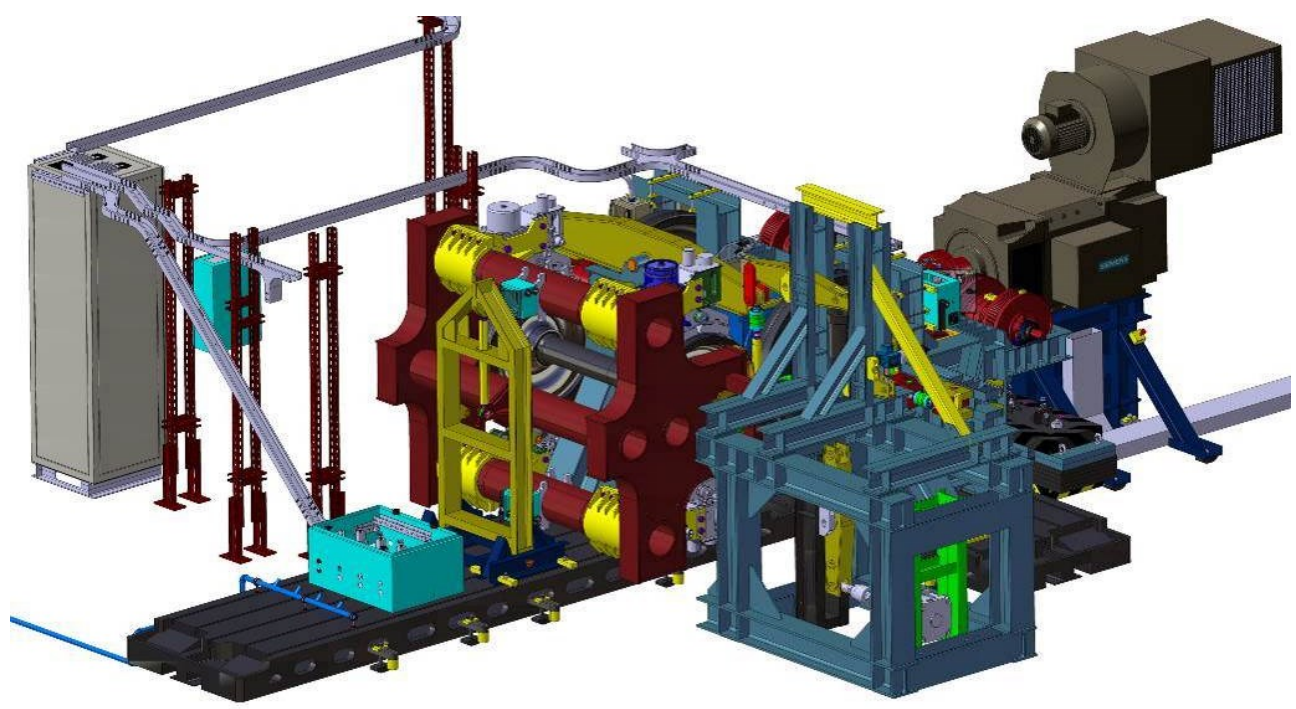

Fig. 1. 3D model of the Test stand RAILBCOT with module SIMRAIL in program CATIA

The purpose of the test consists of two processes. The first is rolling the wheel along the rotating rail. The test stand analyzes the ride characteristics of the wheelset primarily taken from the Y25 chassis with an axle load of $22.5 \mathrm{t}$. The maximum velocity is $160 \mathrm{~km} . \mathrm{h}^{-1}$. The engine has a maximum output power of $434 \mathrm{~kW}$ with a constant torque of $3900 \mathrm{Nm}$.

SIMRAIL (Fig. 1) is a module used to plausibly simulate the phenomena encountered during a ride of a real rail vehicle along a real track (lateral displacement of the wheelset and the change in angle of attack) and for modifying the wheel forces values. Laboratory tests must show similar results to the real Y25 bogie. The laboratory conditions will be comparable to those in real operation. Simulations will take place after several configurations of the operating mode. We will deal with the force effects in the wheelsettrack contact in an arc, ride in a straight track with an empty or loaded vehicle, and also with use of the lateral displacement and the angle of attack of the wheelset.

\section{Reasons for wheel-rail contact cooling}

The RAILBCOT device was designed for long-term tests that show changes in geometry due to the aggressive effect of L and LL brake blocks on the wheelset tread. In such tests, it is necessary to provide sufficient cooling either for the test stand components as well as for 
the tested components. The cooling of the bearings, transmission and the engine is solved by the manufacturer either passively or actively (forced refrigerant circulation). There are two problems with the test pair. The first is the heating of the break block - wheel test pair and the other is the emission of dust particles (Fig. 2A) of the cast iron or the composite material of the brake blocks. In the first problem, the change of friction ratio and the possibility of damaging the wheel-brake block test pair arise due to heat. Because the wheel is driven by the rotating rail via an adhesive bond, the adhesion coefficient may be reduced due to the effect of the deposits and thus the creep between the wheel and the rail can increase (Fig. 2B, 2C).

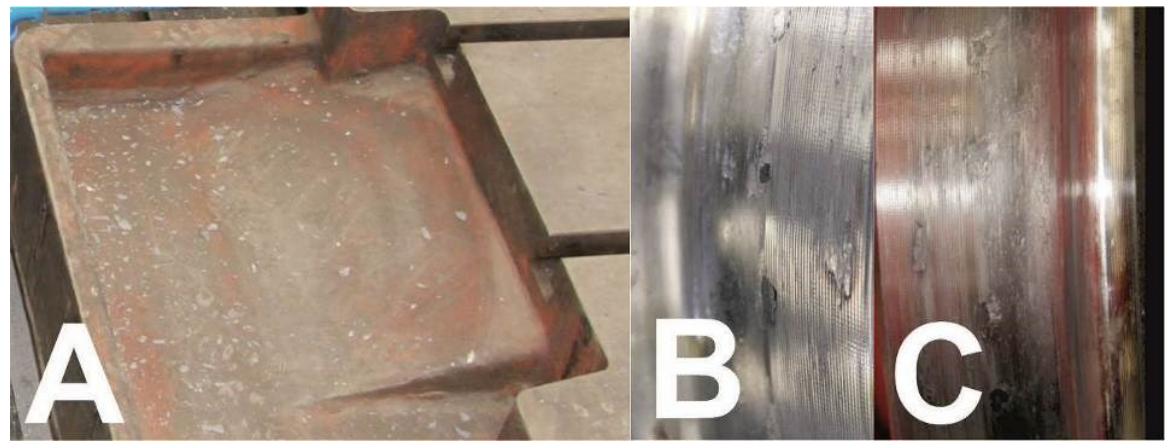

Fig. 2. Emission of the cast iron during braking with an overheated brake block (A) and cast iron sediment on the wheel tread $(B, C)$

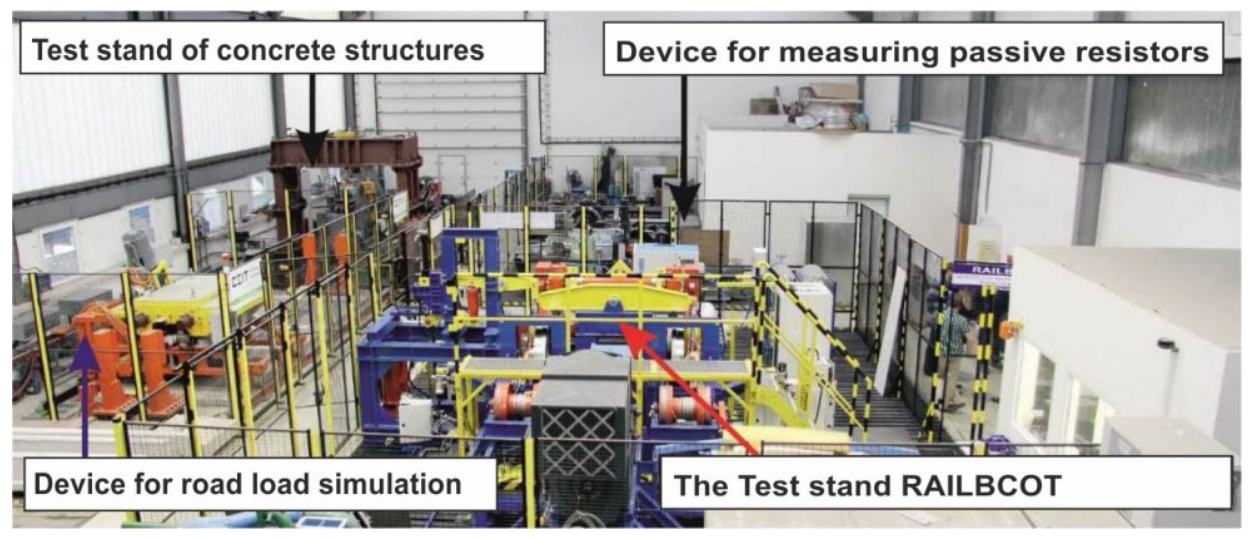

Fig. 3. Test stand RAILBCOT is installed in laboratory BI026

In the event of dust particles being emitted, electrical components may be malfunctioning or shorted. Therefore, all cabinets containing electrical circuits are equipped with an electrical enclosure of IP 65 at least. These particles also have a negative effect on the respiratory tract of the test device's operating staff. It is therefore necessary to eliminate its impact on the staff by using protective equipment (respirators).

Last but not least, it is necessary to take into account the fact that the device is located in a building, where other testing devices for research or teaching purposes are placed as well (Fig. 3). Therefore, for practical reasons, partial or total detachment of the operation area is necessary. Firstly, to protect other test locations and in secondly to protect the RAILBCOT device itself from other devices. The Department of Transport and Handling Machines also has a certificated Inertia braking state UIC. In Fig. 4 shows a view of the test stand and the air tunnel during the braking tests. 


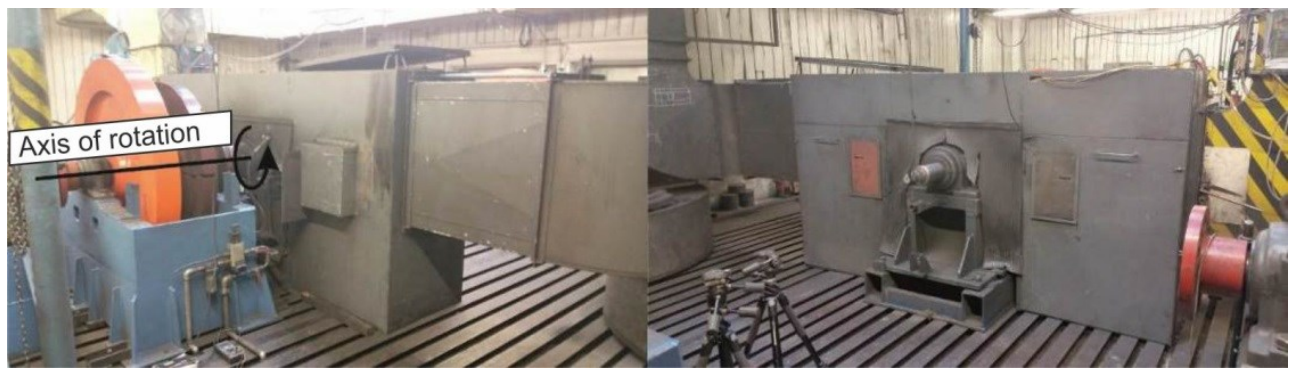

Fig. 4. Inertia braking state UIC

The air tunnel provides a standard-matching airflow around the tested components which at the same time removes dangerous particles from the test area. Two air-blowers control the air flow, which are controlled by turning the throttle. The throttle is controlled by a stepper motor via a worm gear. This configuration also served as a model for the planned RAILBCOT air tunnel.

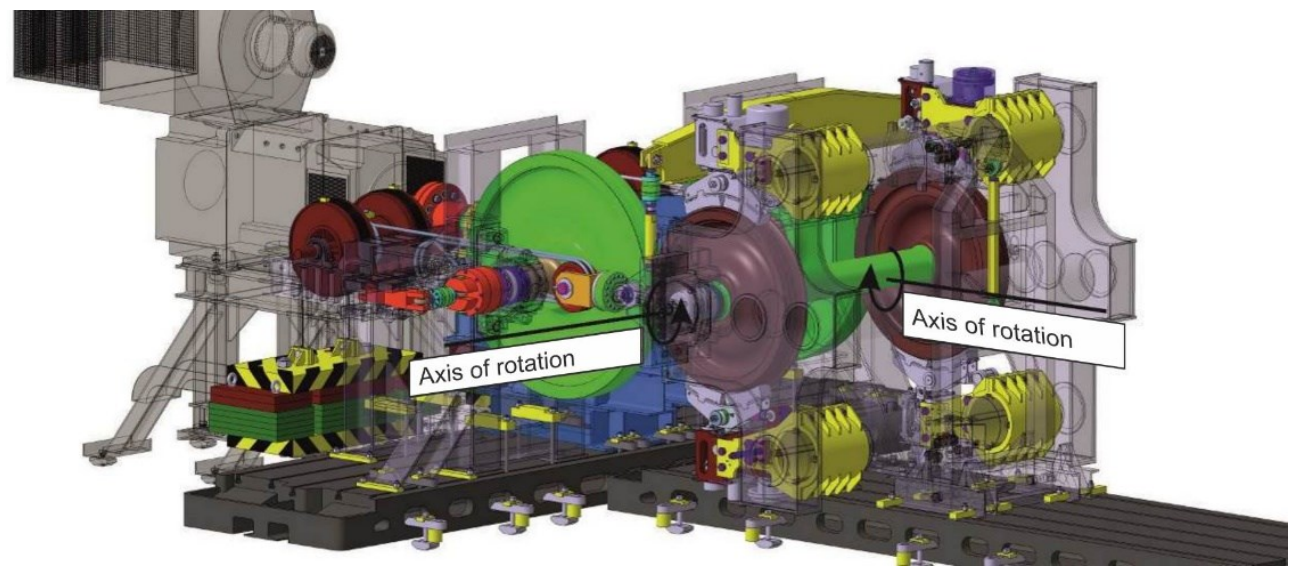

Fig. 5. Test stand of braking components RAILBCOT

The RALBCOT device is more complicated by the fact that the tested wheel in Fig. 4 performs only a rotary movement, the wheelset on Fig. 5, in addition to rotation around the wheelset axis, also performs a swinging movement around the axis of the drive motor. This increases the demands on the air tunnel design. Necessary is also a two-wheel cooling, which as well increases the demands on the fans transporting air to the wheels.

\section{Air-tunnel design}

The design of the pipeline is based on UIC 541-4 standard. For tests up to $80 \mathrm{~km} \cdot \mathrm{h}^{-1}$, it is necessary to achieve a half speed of air above $80 \mathrm{~km} \cdot \mathrm{h}^{-1}$, the required airflow rate is $40 \mathrm{~km} \cdot \mathrm{h}^{-1}$. Therefore, the fan must ensure this speed. For a suitable fan size, we need to know the required flow.

For a maximum velocity of $11.11 \mathrm{~m} \cdot \mathrm{s}^{-1}\left(40 \mathrm{~km} \cdot \mathrm{h}^{-1}\right)$ the following dependency will apply (Fig. 6). As is evident for constant velocity, the flow dependence is linearly dependent on channel area size. For its determination, it is necessary to take into account the dimensional possibilities of the existing structure and also to ensure a fluent flow through the chosen channel. A plausible simulation of airflow conditions requires a solution according to Fig. 7. 


$$
Q=S \cdot v
$$

where:

$Q-$ flow rate $\left[\mathrm{m}^{3} \cdot \mathrm{s}^{-1}\right]$,

$S$ - cross-sectional area of the pipe $\left[\mathrm{m}^{2}\right]$,

$v$ - velocity in the pipe $\left[\mathrm{m} \cdot \mathrm{s}^{-1}\right]$.
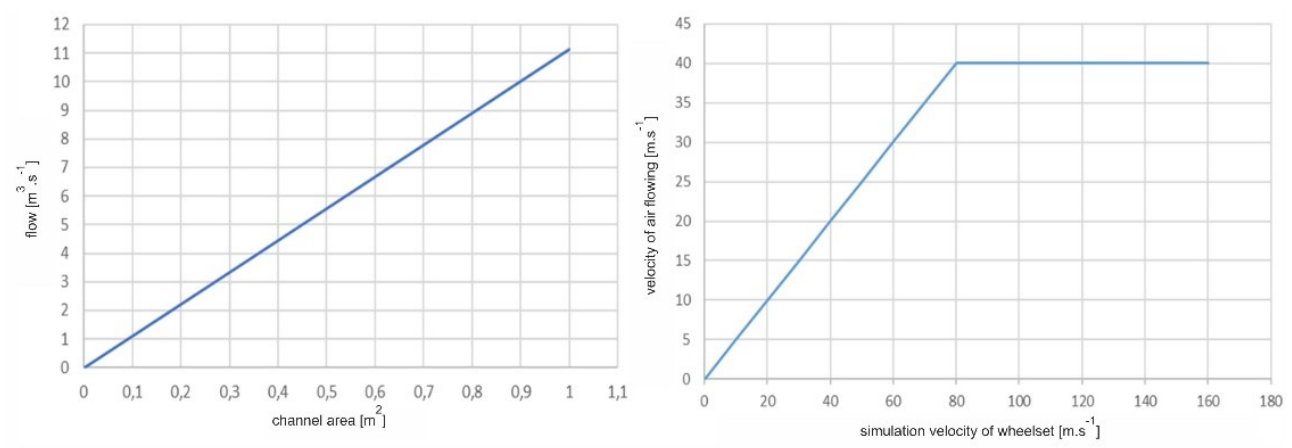

Fig. 6. Dependence between flow and channel cross-section (left) and vehicle velocity and simulated air velocity (right)
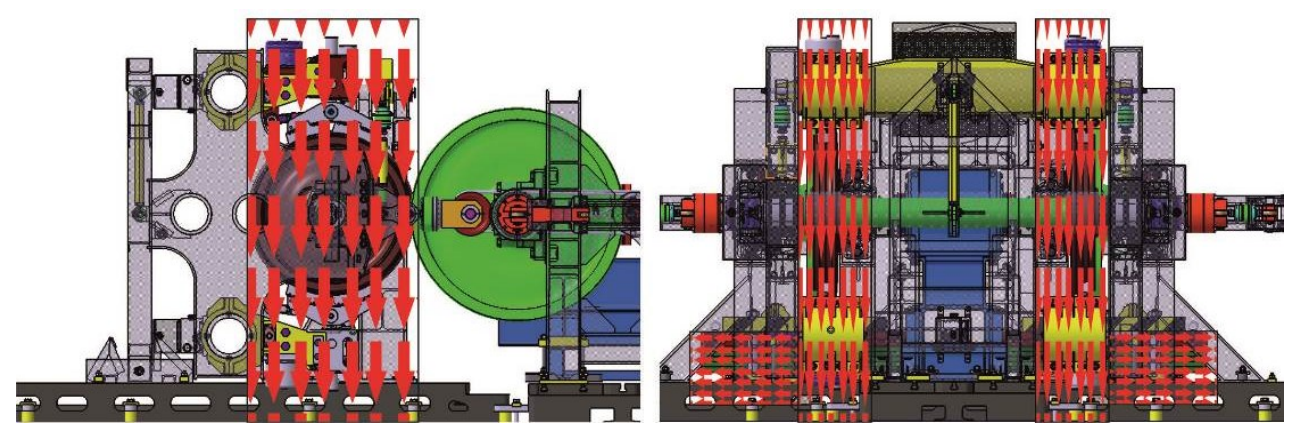

Fig. 7. Original version of the air flow travel

However, this has led to two fundamental problems. When the air flows downwards (see Fig. 7), the flow is suddenly changed by 90 degrees, which would require a suitable deflector, that can not be created for spatial reasons. Such a condition will result in shocks in the airway and thus increase of noise and increase of the load on the whole system. The second problem is the fact that the brake unit does not allow a smooth flow around the wheel and thus its better cooling. In Fig. 8, three cases are illustrated.

Case A represents a half view of the Y25 bogie and its front wheel cover by a buffer beam. The original concept of the test stand was based on simulating this type of bogie, as it is a standardized bogie for use on European tracks. Therefore, the design according to position B would not be satisfactory from the point of view of the directly circumflown area. 


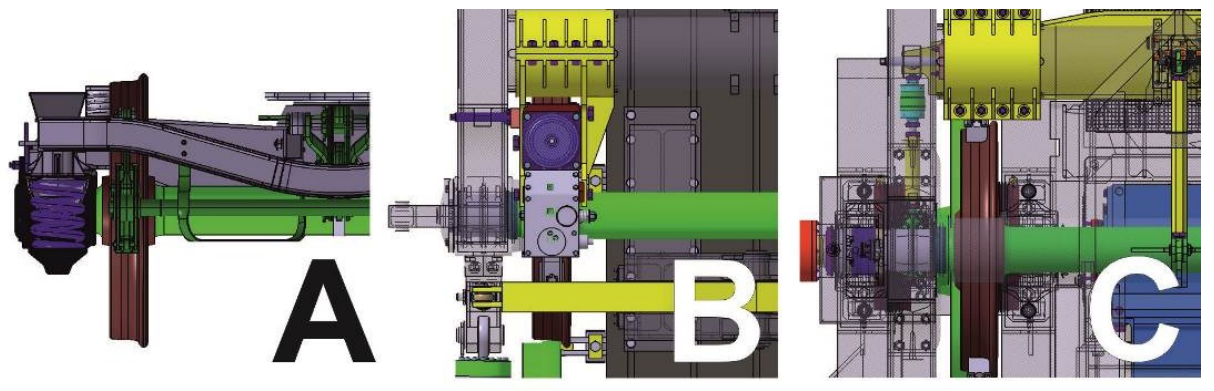

Fig. 8. Barriers in the air flow for different variations

Therefore, we chose a variant according to position C. Here the overlap is smaller and the surface of the wheel directly cooled by the air intake is similar to that of position A.
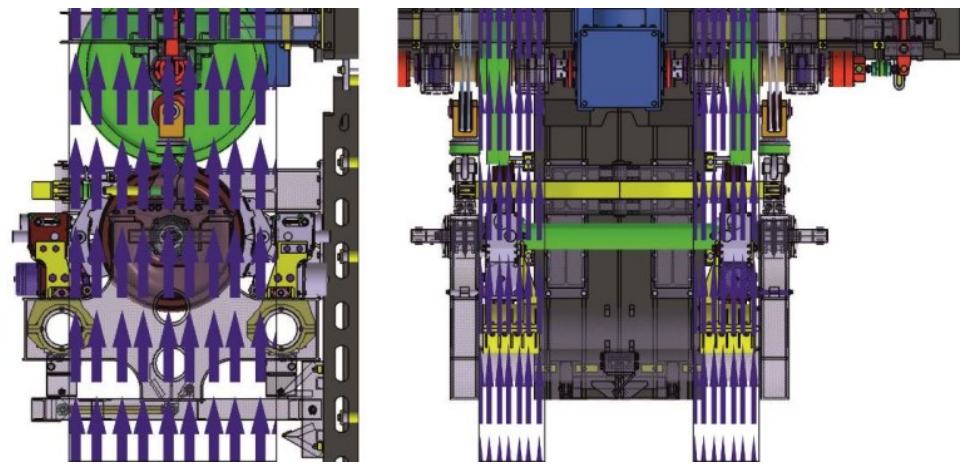

Fig. 9. Adjusted variant of wheelset cooling solution

In addition, in this variant, the air can also be used to cool the rotating rail, which in the case of the previous variant would require additional ventilation equipment (Fig. 9). The disadvantage of this solution is the fact that with only one source, at zero flow, the rail is without cooling.
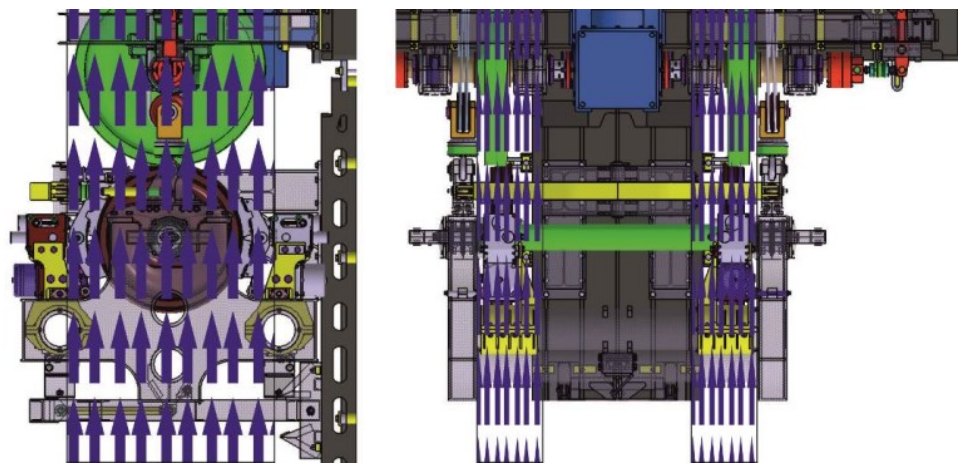

Fig. 10. Virtual air channel view

Fig. 10 shows the path of the air flowing around the wheel. This is only a basic assumption because the frame can be rotated about a $60 \mathrm{mrad}$ angle around the motor's longitudinal axis. It is necessary to create this path by means of guide plates and enclosing the whole device in a package made up of steel profiles, into which boards of noiseabsorbing material will be inserted. 
The projected flowrate required for the fan dimensioning will be according to the dimensions of the channel from Fig. 10 determined using the equation (1) as follows.

$$
Q=S \cdot v=a \cdot b \cdot v=1.35 \cdot 0.438 \cdot 11.111=6.5699 \mathrm{~m}^{3} \cdot \mathrm{s}^{-1}=23651 \mathrm{~m}^{3} \cdot \mathrm{h}^{-1}
$$

It is therefore necessary to install at the inlet two fans with a flow rate of $6.6 \mathrm{~m}^{3} . \mathrm{s}^{-1}$ or one with a flow of $13.2 \mathrm{~m}^{3} \cdot \mathrm{s}^{-1}$.

Such a channel is, however, only virtual since its construction is demanding for manufacture and since it is necessary to maintain the possibility of relative movement between the movable frame with the wheelset and the static frame. Therefore, the channel will be designed as a set of routing plates and a protective structure will be used to ensure the insulation of the device from the surrounding area, which will also reduce the noise produced by the device.

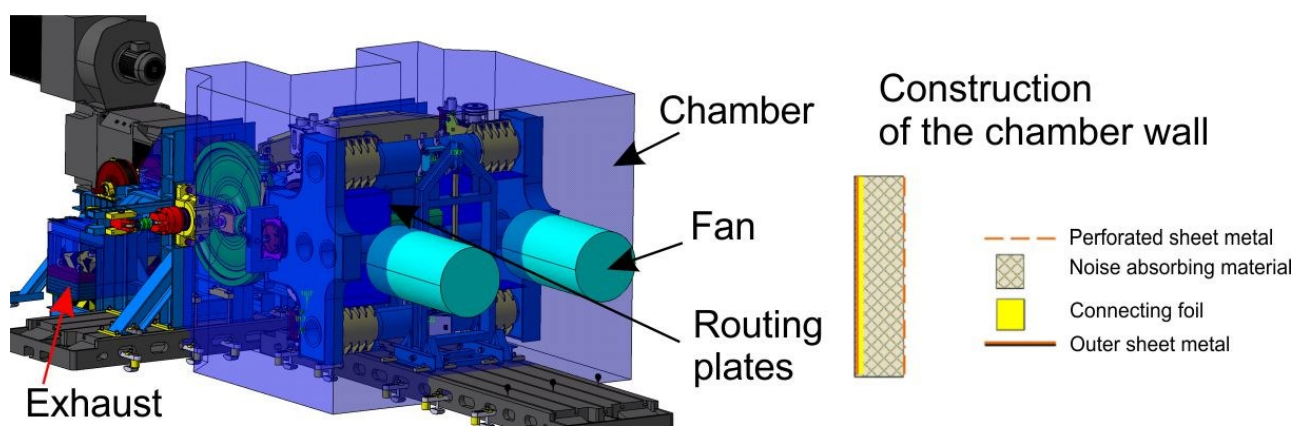

Fig. 11. Protection chamber

As can be seen in Fig. 11, the air is blown into the protection chamber by a pair of fans, where it is driven by the routing plates to the rotating axle. From there, the air is transported by the channel into the exhaust where it is cleaned in the filter and proceeds to the outer area, or it will be drained outside the laboratory. The wall of the chamber is made up of a frame structure, that is filled with metal boxes. These boxes contain noise absorbing material.

\section{Conclusion}

In our article, we have conceptually defined the basic parameters for the design of the wheel-brake block pair circumfluence. The presented problem is just an introduction to a more detailed design of the final device construction. In the next step, it will be necessary to determine the nature of the flow in the proposed channel using CFD analysis and to determine the dimensions and shapes of the exhaust. It is also necessary to choose an efficient filter at the end of the exhaust which will separate the dust particles from the air after braking.

The work was supported by the Cultural and Educational Grant Agency of the Ministry of Education of the Slovak Republic in project No. KEGA 077ŽU-4/2017: Modernization of the Vehicles and engines study program. The work was also supported by the project No. APVV-0842-11: Equivalent railway operation load simulator on the roller rig and VEGA No. 1/0927/15: Research of the use of alternative fuels and hybrid drives on traction vehicles with aim to reduce fuel consumption and air pollutants production.

Research-Educational Centre of Rail Vehicles (VVCKV) 


\section{References}

1. M. Blatnický, M. Štauderová, J. Dižo, Numerical analysis of the structure girder for vehicle axle scale calibration. Procedia Engineering 177, 510-515 (2017)

2. J. Dižo, Analysis of a goods wagon running on a railway test track. Manufacturing technology: journal for science, research and production 16 (4), 667-672 (2016)

3. J. Dižo, M. Blatnický, B. Skočilasová, Computational modelling of the rail vehicle multibody system including flexible bodies. Communications: scientific letters of the University of Žilina 17 (3), 31-36 (2015)

4. J. Gerlici, M. Gorbunov, K. Kravchenko, A. Kostyuchevich, O. Nozhenko, T. Lack, Experimental rigs for wheel / rail contact research. Manufacturing technology: journal for science, research and production 16 (5), 909-916 (2016)

5. J. Gerlici, M. Gorbunov, K. Kravchenko, R. Domin, M. Kovtanets, T. Lack, Slipping and skidding occurrence probability decreasing by means of the friction controlling in the wheel-braking pad and wheel-rail contacts. Manufacturing technology: journal for science, research and production 17 (2), 179-186 (2017)

6. J. Gerlici, T. Lack, Railway wheel profile development based on the geometric characteristics shapes. In Contact mechanics and wear of rail/wheel systems = CM2009: $8^{\text {th }}$ international conference: $15^{\text {th }}-18^{\text {th }}$ September 2009, Firenze, Italy, ISBN 978-88-904370-0-7, 961-967 (2009)

7. J. Gerlici, T. Lack, Rail geometry analysis (from the point of view of wearing in the operation). Communications - scientific letters of the University of Žilina 5 (1), 43-51 (2003)

8. J. Gerlici, T. Lack, Rail vehicles brake components test bench utilisation. Applied mechanics and materials 486, 379-386 (2014)

9. J. Gerlici, T. Lack, Modified HHT method for vehicle vibration analysis in time domain utilisation. In Applied mechanics and materials 486, 396-405 (2014)

10. J. Gerlici, T. Lack, Railway wheel and rail head profiles development based on the geometric characteristics shapes. Wear: An international journal on the science and technology of friction, lubrication and wear 271 (1-2), 246-258 (2011)

11. J. Gerlici, T. Lack, Contact geometry influence on the rail / wheel surface stress distribution. Procedia Engineering 1, 2249-2257 (2010)

12. J. Gerlici, T. Lack, Railway wheelset and track contact. 200 p., ISBN 80-8070-317-5, (EDIS - University of Žilina publishers, Žilina, 2004) [in Slovak]

13. J. Gerlici, T. Lack, Transport Means Properties Analysis. Vol. I. 214 p., ISBN 808070-408-2 (EDIS - University of Žilina publishers, Žilina, 2005)

14. T. Lack, J. Gerlici, Railway wheel and rail roughness analysis. Communications: Scientific Letters of the University of Žilina 11 (2), 41-48 (2009)

15. T. Lack, J. Gerlici, Wheel/rail tangential contact stress evaluation by means of the modified strip method. Communications : scientific letters of the University of Žilina 16 (3A), 33-39 (2014)

16. T. Lack, J. Gerlici, Tangential stresses for non-elliptical contact patches computed by means of a modified FASTSIM method. Civil-Comp Proceedings 1, [online] (2016)

17. T. Lack, J. Gerlici, The FASTSIM method modification in speed up the calculation of tangential contact stresses between wheel and rail. Manufacturing technology: journal for science, research and production 13 (4), 486-492 (2013) 
18. T. Lack, J. Gerlici, J. A modified strip method to speed up the calculation of normal stress between wheel and rail. Applied mechanics and materials 486, 359-370 (2014)

19. T. Lack, J. Gerlici, A modified strip method to speed up the tangential stress between wheel and rail calculation. Applied mechanics and materials 486, 371-378 (2014)

20. P. Pecháč, M. Sága, Controlling of local search methods' parameters in memetic algorithms using the principles of simulated annealing. Proc. Eng. 136, 70-76 (2016)

21. A. Sapietová, M. Sága, P. Novák, R. Bednár, J. Dižo, Design and application of multisoftware platform for solving of mechanical multi-body system problems. Mechatronics: Recent technological and scientific advances, 345-354 (2011)

22. M. Sága, R. Bednár, M. Vaško, Contribution to modal and spectral interval finite element analysis. Vibration Problems ICOVP 2011, Springer Proceedings in Physics 139, 269-274 (2011) 